\title{
Erratum to: Developing a fatigue fracture model for asphalt overlay reinforced with geogrid
}

\author{
Shahab Fallah • Ali Khodaii
}

Published online: 30 April 2015

(C) RILEM 2015

\section{Erratum to: Materials and Structures DOI 10.1617/s11527-015-0606-6}

Due to an unfortunate turn of events the wrong version of Table 3 was published. Please find in this erratum the correct version of Table 3 that should be regarded as the final version by the reader.

Table 3 Aggregate grading

\begin{tabular}{|c|c|c|c|c|c|c|c|c|c|c|}
\hline No & Sieve size $(\mathrm{mm})$ & 37.5 & 25 & 19 & 12.5 & 9 & 4.75 & 2.36 & 0.3 & 0.075 \\
\hline \multicolumn{11}{|c|}{ Aggregate grading for existing asphalt concrete } \\
\hline 1 & Passing $(\%)$ & 100 & 95 & - & 70 & - & 35 & 24 & 9 & 5 \\
\hline 2 & & & 100 & 95 & - & 78 & 56 & 38 & 13 & 7 \\
\hline 3 & & & & 100 & 95 & - & 62 & 42 & 12 & 6 \\
\hline \multicolumn{11}{|c|}{ Aggregate grading for asphalt overlay } \\
\hline 1 & Passing $(\%)$ & & & 100 & 95 & - & 62 & 42 & 12 & 6 \\
\hline 2 & & & & & 100 & 91 & 85 & 45 & 15 & 7 \\
\hline 3 & & & & & 100 & 91 & 76 & 50 & 15 & 8 \\
\hline
\end{tabular}

The online version of the original article can be found under doi:10.1617/s11527-015-0606-6.

\section{S. Fallah}

Highway Division, Department of Civil and

Environmental Engineering, Amirkabir University of

Technology, Tehran, Iran

e-mail: shfallah@aut.ac.ir

\section{A. Khodaii ( $\square)$}

Department of Civil and Environmental Engineering, Amirkabir University of Technology, Tehran, Iran e-mail: khodaii@aut.ac.ir 